
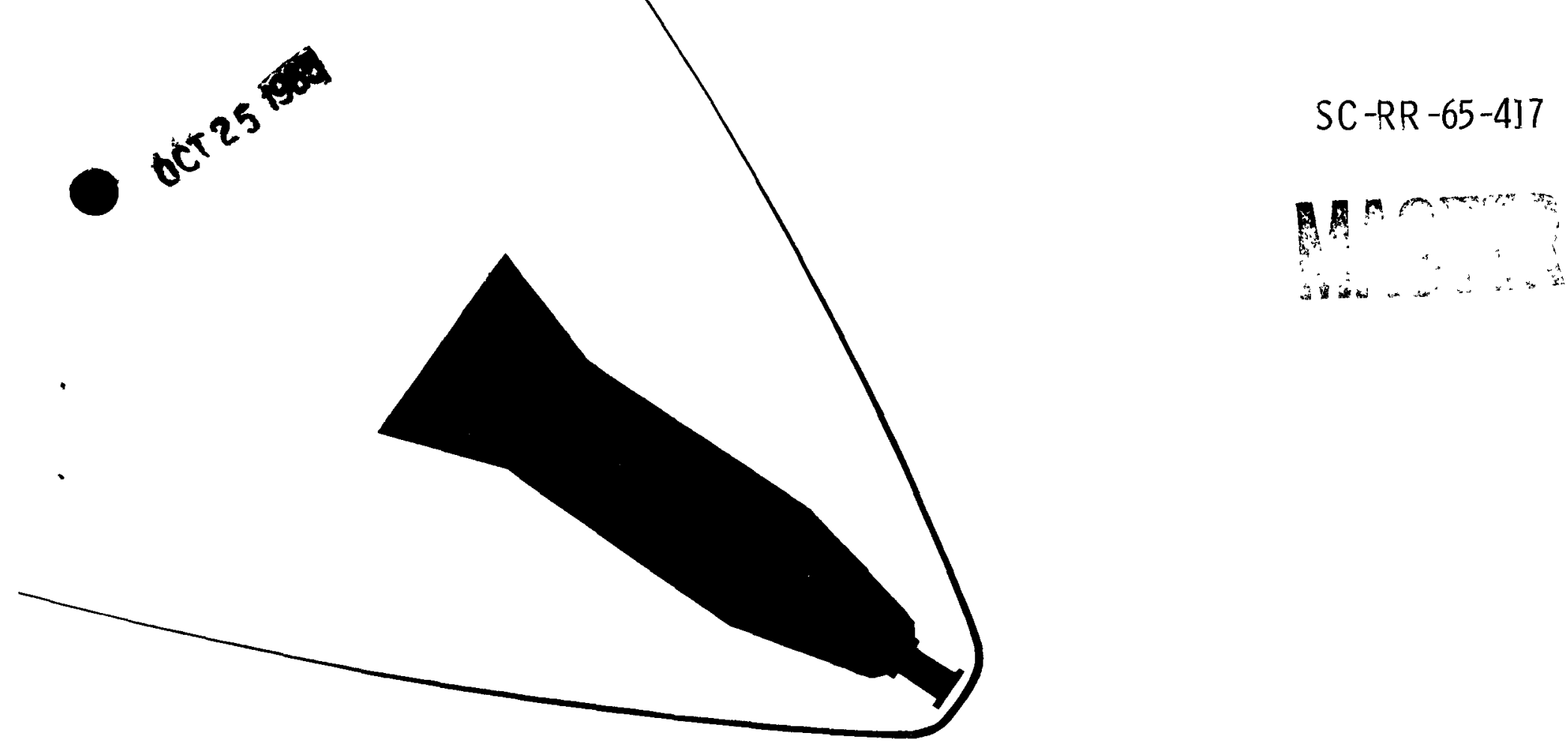

\title{
AEROSPACE NUCLEAR SAFETY
}

\section{AEROSPACE NUCLEAR SAFETY: PROBABILITY ANALYSIS OF REACTOR POWER LEVEL AND DOSE RATE}

D. G. Kitzinger, 9312

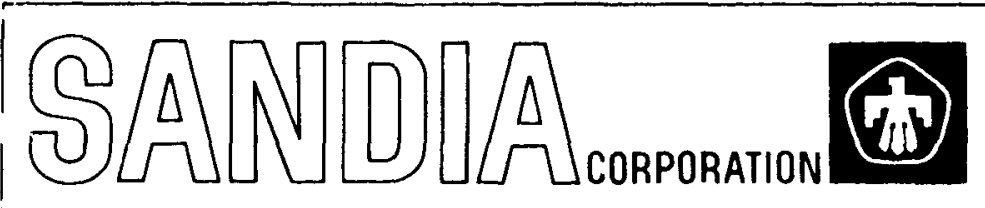

PRIME CONTRACTOR TO THE UNITED STATES ATOMIC ENERGY COMMISSION ALBUQUERQUE. NEW MEXICO LIVERMORE, CALIFORNIA 


\section{DISCLAIMER}

This report was prepared as an account of work sponsored by an agency of the United States Government. Neither the United States Government nor any agency Thereof, nor any of their employees, makes any warranty, express or implied, or assumes any legal liability or responsibility for the accuracy, completeness, or usefulness of any information, apparatus, product, or process disclosed, or represents that its use would not infringe privately owned rights. Reference herein to any specific commercial product, process, or service by trade name, trademark, manufacturer, or otherwise does not necessarily constitute or imply its endorsement, recommendation, or favoring by the United States Government or any agency thereof. The views and opinions of authors expressed herein do not necessarily state or reflect those of the United States Government or any agency thereof. 


\section{DISCLAIMER}

Portions of this document may be illegible in electronic image products. Images are produced from the best available original document. 
SC-RR-65-417

AEROSPACE NUCI,EAR SAFETY: PROBABILITY ANAI.YSIS OF

REACTOR POWER LEVEL AND DOSE RATE

D. G. Kitzinger, 9312

Sandia Laboratory, Albuquerque

RELEAASED FOR ANWOUNCEMENT

IN IUCLEAR SCIENCE ABSTRACTS

October 1965

\section{ABSTRACT}

This study quantizes the probability spaces of power versus time and of dose rate versus time for a reactor operated in space. These probability functions ald in the determination of safety. 


\section{SUMTTARY}

Determination of the inazards associated wita the operation of an Auxiliary Power Unit (APU) in space requires knowledge of taxe nuelear performanee of tore reactor. Because of the large number of accudents that mignt occur chring the complete space mission, eacn type of accident carries a probability tag; and because the nazard associated wita a particular aceident has meaning only in lign of its probability, it is logical to define probabilities for cacil important nuclear property w in '1 may afferet the magnitucie of the nazard. Reactor power level and dose potential, as functions of time, are defined in this stud lo a probabilistic sense by considering variations in initial ecquilibrium power level as well as in anangine coolant flow rates. The matiematies deseribed may be extended to include other ceferts whe mat be important to a particular reactor in spate. A CDC 3600 computer code, DECII) performs all numerical integrations, interpolations, and extrapolations neecssary to define tue generalized probabilits spaces for reactor power level and dose rate. 


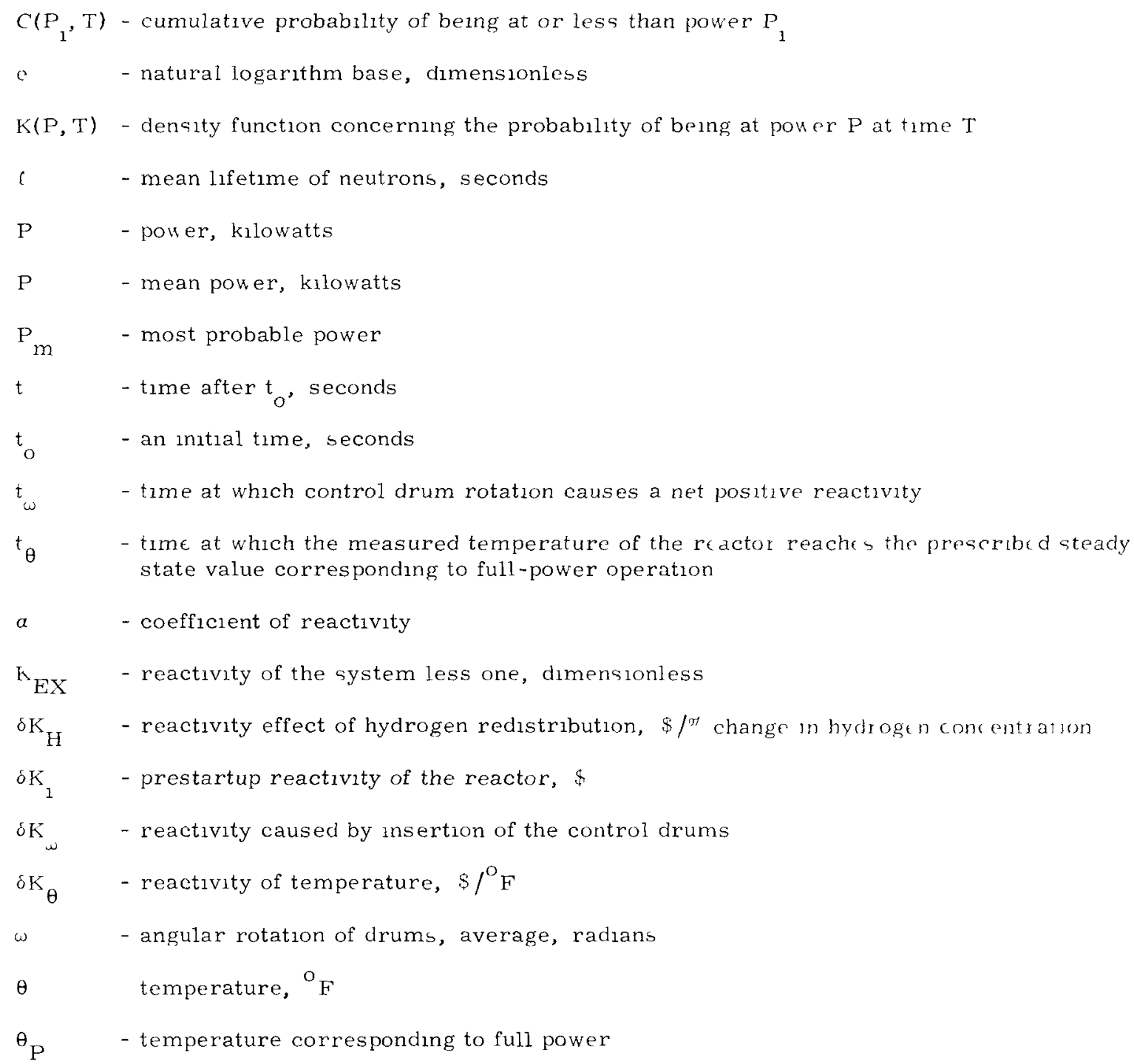




\section{ALROSPACH: NUCLFAR SAFETY: PROBABILITY ANALYSIS OF RFACTOR POWER I.EVEL AND DOSE RATE}

\section{Introduction}

In order to perform an analysis of the hazards associated with the operation of an auxiliary power unit $\left(A P{ }^{\prime}\right)$ reactor in orbit, it is necessary to obtain fission product inventory for many situations and then to provide a proper weight for each situation with its probability of occurrence. Since fission product inventory is a function of reactor power history, it is necessary to determine and/or predict performance characteristics of the reactor systom.

The power in the APU reactor as presently envisioned is a function of many things, most important of which are reactor geometry, temperature, coolant flow rate degradation, hydrogen moderator redistribution, and fuel burnup. Each quantity mentioned has an influence on reactor power best expressed in terms if reactivity, a measure of time rate of change of reactor power. A list of terms and symbols used in this discussion is included in this report.

\section{Analysis}

The basic equation of reactor kinetics ${ }^{(1)}$ is expressed as:

$$
P(t)=P\left(t_{0}\right) e^{K} E X\left(t-t_{0}\right) / \ell
$$

Since $\left(\sim 10^{-6}\right.$ seconds, $K_{E X}$ must be very small if $P(t)$ is to be a slowly changing function of time. In particular, if power decreases by a factor of e in $10^{8}$ seconds (about 3 years), then $\overline{\mathrm{K}}_{\text {F.X }} \simeq-10^{-14}$ over this time period.

Each quantity affecting excess reactivity should be cvaluated qualitatively. The gcometry effect is caused by the precise geometry of the reactor as a function of time. Only during startup does the geometry change, in the sense that other changes in the geometry after startup including hydrogen redistribution and fuel burnup are considered separately in this analysis. The change of geometry at startup is due to crntrol drum rotation. At initial startup,

$$
\begin{aligned}
\mathrm{K}_{\mathrm{EX}} & =-\delta \mathrm{K}_{\mathrm{i}}+\delta \mathrm{K}_{\omega} \\
& =-\delta \mathrm{K}_{\mathrm{i}}+\boldsymbol{\alpha}_{\omega} \omega
\end{aligned}
$$

(1) Glasstone, Edlund, The Elements of Nuclear Reactor Theory, p。 293. 
Tests have shown, that for some value of $\omega, \mathrm{K}_{\mathrm{FX}}>0$; hence, at some time, $\mathrm{t}_{\omega}$, the reactor will become active or supercritical.

At $t_{\omega}, P\left(t_{\omega}\right)$ is very small $\left(\sim 10^{-6}\right.$ watts); however, increase in power level as given in liquation 1 causes heat to be generated which results in a temperature rise. Including the temperature effect on reactivity,

$$
\begin{aligned}
K_{E X} & =-\delta \mathrm{K}_{i}+\delta K_{\omega}-\delta \mathrm{K}_{\theta} \\
& =-\delta \mathrm{K}_{i}+a_{\omega} \omega-a_{\theta} \theta .
\end{aligned}
$$

Note that increase in temperature results in a decrease of reactivity which must be offset by additional drum rotations. As will be shown later, the effects of coolant flow rate degradation, hydrogen redistribution, and fuel burnup occur only after long full-power operation; hence, they can be ignored for the relatively short startup period. Since active control of the reactor by drum rotation is limited, a mechanism for obtaining desired power is incorporated in the reactor. A temperature measuring sensor is used to prevent changes in $w$ after a prescribed temperature is reached. At this time, since $\mathrm{K}_{\mathrm{EX}} \sim 0$,

$$
\omega=\frac{\delta \mathrm{K}_{\mathrm{i}}+a_{\theta} \theta_{\mathrm{P}}}{\alpha_{\omega}}
$$

A density function has been assumed to describe the initial equilibrium power level and the power level at later times after active control is ended. Any density function that satisfies the relationship $\int_{0}^{\infty} K(P, T) d P=1$ may be chosen; additional information might be expected to refine the density function.

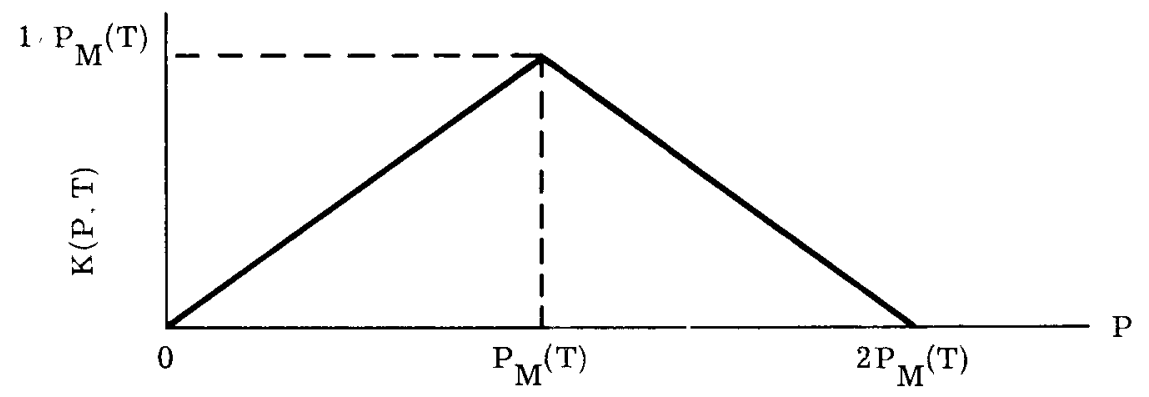

Figure 1. Initial Fiquilibrium Power Level Influence on Later Powers

The density function in Figure 1 was chosen because it is believed that a distribution of powers may exist of the approximate width zero to $2 \mathrm{P} \mathrm{m}$. The determination of the exact distribution function demands understanding of the coupled heat transfer, fluid flow, electrical, vibrational, reactor kinetic, and mechanical design problems. Essentially, the exact proportionality of indicated temperature to power level is a function of the above problem areas; only by studying the probability of obtaining variations from expected bchavior in these arcas can the distribution function be obtained exactly. An abbreviated list of influcnces is given. 
1. Vibration during launch constricts or expands the coolant flow stream incident on the temperature sensor this results in a hot or cold sensor reading which causes a low-or high power level, respectively.

2. Vibration during launch or faulty installation causes a misinterpretation of the temperature signal so that either a high-or a low temperature results in a low or high power, respectively.

3. The rate of insertion of reactivity exceeds design expectations so that a rapid but nondestructive power transient with a corresponding temperature transient results. This is caused by an un expected mechanical configuration change and can result in either a low - or a high-power level dependent on the magnitude of the power, temperature at the sensor, and control drum rotation time lags.

4. Calibration of the actual flight reactor as a function of sensor temperature, $\theta_{P}$, cannot be com plete since transients in reactor power, fluid flow, and heat transfer must be eliminatcd by relatively long operation at design power. Such operation would result in a relatively large fission product inventory and would thus make prelaunch handling of the reactor hazardous.

It is noted that $\mathrm{K}(\mathrm{P}, \mathrm{T})$ is only related to $\mathrm{P}_{\mathrm{m}}(\mathrm{t})$. Since a property of the density function is that $\int_{0}^{P^{\prime}} K(P, T) d P=$ cumulative probability of being at or less than power $P^{\prime}$ at time $T$, note that the maximum power corresponding to a given probability is proportional to $\mathrm{P}_{m}(\mathrm{t}) 。 \mathrm{P}_{\mathrm{m}}(\mathrm{t})$ is defined by $K_{E X}(t)$ which is related to time-power history. Higher power operation results in greater fuel burnup and hydrogen redis tribution and hence in a more rapid time rate of decrease in $\mathrm{K}_{\mathrm{EX}}$ with corresponding faster degradation of power with time. Therefore, this physical reasoning defends the assumption concerning the effect of initial equilibrium power level on power for all succeeding times

It has been hypothesized that removal of hydrogen from its zirconıum-hydride lattıce 15 accompi 1 she $d$ only with addition of energy. The amount of energy required is related to temperature and pressure conditions as well as physical properties of the mixture. In addition to the energy required to cause hydrogen release, a potential barrier restricting release must be overcome. Hence, at design temperature and pressure, only small amounts of hydrogen are expected to evolve. As a consequence of performing critıcal experiments on reactors of varying hydrogen composition, a reactivity coefficient of hydrogen percentage composition was determined. The incorporation of this coefficient to describe hydrogen redistribution rather than removal is an assumption that is open to question although the alternate calculation is difficult.

Fuel burnup contributes a negative reactivity which is directly related to time-at-poner operation. This calculation must consider the two-dimensional long-time flux variation together with flux weighting factors to arrive at the reactivity coefficient for fuel burnup percentage.

Long-time power behavior as a function of varıous assumptions concerning NaK coolant flow degradatıon has been predicted by one agency. Their analysis considers each event affecting reactivity as being well and uniquely defined. Actually, probabilities concerning variations in every step in the analysis may be esti mated to define a probability space of power versus time. A step toward the goal of obtaining a generalized power-time probability space is illustrated in Figure 1 for initial power variation alone. The probability space influence due to hydrogen redistribution and fuel burnup has not been considered. Since consideration will not be made for variations in power history due to possible variations in hydrogen redistribution and fuel 
burnup, the power history mentioned above, with modifications made for initial power variation and assumptions concerning NaK flow degradation, will be accepted.

NaK flow degradation has a direct influence on power level due to the coupling between heat transfer, fluid flow, and temperature coefficient of reactivity. Because of the strong temperature dependence in Equation 3, the temperature of the coolant remains essentially constant. However, heat removed is directly proportional to coolant flow rate when coolant temperature is constant. As a consequence, if coolant flow rate decreases, the heat removed is less and so the heat produced must be less. Heat produced is directly proportional to power level alone; hence, power level degradation is directly proportional to flow rate degradation. As flow rate becomes small, the mechanism of radiant heat transfer directly from the reactor vessel becomes significant, and so reactor power remains at a substantial power for very long periods of time.

Our assumption regarding NaK flow degradation is based upon predicted power curves at no degradation and at 5 percent degradation/year. The density function for NaK degradation is given in Figure 2.

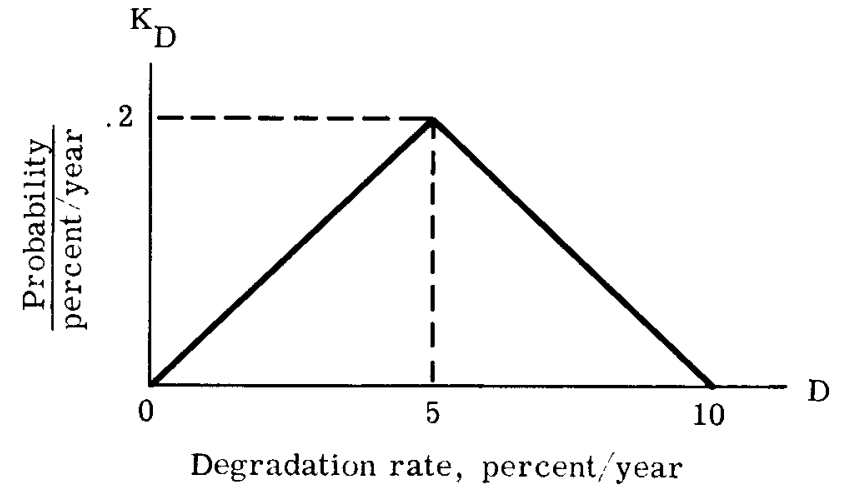

Figure 2. Density Function for NaK Coolant Degradation Rate

The basis for this assumption is:

1. The assumed coolant flow degradation rate is 5 percent, which dictates the most probable degradation rate.

2. Tests run by a government agency on the NaK pumps indicate that much higher degradation rates are possible, especially immediately following startup of the pumps.

3. Evidence of a steady-state sizable pumping rate after long operating times support zero degradation rate assumptions.

The power versus time probability space may be assembled with the assumptions as given. The assumed power curve may be expressed as

$$
P_{m}=\exp \left(\sum_{i=0}^{n} b_{i} \ell n^{i} t\right),
$$


where the appropriate $b_{i}$ coefficients are evaluated to match closely the power curve. It should be noted that a different set of coefficients is used for the 5 percent degradation/year than for the zero degradation/year power curve. In Equation 5, the density distribution for initial equilibrium power may be devejoped.

$$
K(P . T)=\frac{1}{P_{m}(T)}-\left|\frac{P_{m}(T)-P(T)}{P_{m}^{2}(T)}\right|, P(T)<2 P_{m}(T)
$$

Notice that

$$
\int_{0}^{2 \mathrm{P}} \mathrm{m}(\mathrm{T})
$$

that is, that the reactor is certainly operating at some power between zero and $2 \mathrm{P}_{\mathrm{m}}(\mathrm{T})$. The NaK flow degradation density function is:

$$
\mathrm{K}_{\mathrm{D}}=0.2-0.04|5-\mathrm{D}|, \mathrm{D} \leq 10
$$

so that

$$
\int_{0}^{10} K D d D=1
$$

or, the degradation rate is certainly between 0 and 10 . Equation 6 is valid for each degradation rate at which $\mathrm{P}_{\mathrm{m}}(\mathrm{T})$ is defined. Since Equation 5 is used to determine $\mathrm{P}_{\mathrm{m}}(\mathrm{t})$ at either $\mathrm{D}=0$ or $\mathrm{D}=5$, linear interpolation for $\mathrm{P}_{\mathrm{m}}(\mathrm{t})$ for $0<\mathrm{D}<5$ and geometric extrapolation for $\mathrm{P}_{\mathrm{m}}(\mathrm{t})$ for $5<\mathrm{D}<10$ may be performed, thus making Equation 6 valid at all NaK flow degradation rates. A weighting of the power history probability space may be accomplished to account for the probability of variation in NaK flow degradation rate.

$$
K(P, T)=\frac{\int_{0}^{10} K_{D} K(P, T, D) d D}{\int_{0}^{10} K_{D} d D}-\int_{0}^{10} K_{D} K(P, T, D) d D
$$


where $\mathrm{B}(\mathrm{P}, \mathrm{T}, \mathrm{D})$ is obtained from Equation 6 for particular values of $\mathrm{T}$ and $\mathrm{D}$. The restraint given in Equation 7 is satisfied:

$$
\begin{aligned}
\int_{0}^{2 P_{m}^{(t)}} K(P, T) d P & =\int_{0}^{2 P} \int_{0}^{(t)} K_{D} K(P, T, D) d D d P \\
& =\int_{0}^{10} K_{D} \int_{0}^{2 P} K(P, T, D) d P d D
\end{aligned}
$$

out

$$
\left.\int_{0}^{2 \mathrm{P}} \mathrm{m}(\mathrm{t}) \mathrm{P}, \mathrm{T}, \mathrm{D}\right) \mathrm{dP}=1 \text {, similar to Equation } 7
$$

Therefore,

$$
\int_{0}^{2 P_{m}^{(t)}} K(P, T,) d P=\int_{0}^{10} K{ }_{D} d D=1
$$

When the power history probability space, $K(P, T)$, is defined, either mean power or maximum power at cumulative probability may be determined.

$$
\begin{aligned}
& \bar{P}(T)=\int_{0}^{2 P_{m}^{(T)}} P(T) K(P, T) d P \\
& C\left(P_{i}, T\right)=\int_{0}^{P_{i}} K(P, T) d P
\end{aligned}
$$

Equation 13 is solved for $\mathrm{P}_{i}$ if one wishes to find the power history at given cumulative probability. A computer program called DECIDE has been written for the Sandia Corporation CDC 1604 Computer which performs the operations required in generating histories of mean power and maximum power with cumulative probability. The equations described above are integrated numerically, and extensive information on the power history probability space is provided. Reference to equations used above shall be made.

$$
P_{m}(D, T)=\exp \left(\sum_{i=0}^{n} b_{i}(D) \ln { }^{i} t\right)
$$


The predicted power histories at $D=0$ and $D=5$ were used to establish the coefficients $b_{1}(0)$ and $b_{i}(5)$. The Sandia Corporation code M-151, (2) which is capable of defining these coefficients, was used in this capacity. When the coefficients are defined, power at any time at either $\mathrm{D}=0$ or 5 may be found. Power at any time and $0<\mathrm{D}<5$ is obtained by linear interpolation:

$$
P_{m}(D, T)=P_{m}(O, T)+\frac{D}{5}\left[P_{m}(5, T)-P_{m}(O, T)\right] \text {. }
$$

When $5<D<10$, geometric extrapolation is performed:

$$
\mathrm{P}_{\mathrm{m}}(\mathrm{D}, \mathrm{T})=\frac{\mathrm{P}_{\mathrm{m}}^{2}(5, \mathrm{~T})}{\mathrm{P}_{\mathrm{m}}(\mathrm{O}, \mathrm{T})+\frac{10-\mathrm{D}}{5}\left[\mathrm{P}_{\mathrm{m}}(5, \mathrm{~T})-\mathrm{P}_{\mathrm{m}}(\mathrm{O}, \mathrm{T})\right]}
$$

Thus, mean power history is defined for any NaK coolant degradation rate.

Equation 6 is modified to be a function of $D$.

$$
K(P, T, D)=\frac{1}{P_{m}^{-}(D, T)}-\left|\frac{P_{m}(D, T)-P(D, T)}{P_{m}^{2}(D, T)}\right|, P(D, T)<2 P_{m}(D, T)
$$

Equation 8 is not changed.

$$
\mathrm{K}(\mathrm{D})=\frac{1}{5}\left(1-\frac{|5-\mathrm{D}|}{5}\right)=0.2-0.04|5-\mathrm{D}|, \mathrm{D}<10
$$

Equation 10 is evaluated numerically.

$$
K(P, T)=\int_{0}^{10} K(D) K(P, T, D) d D=\sum_{1=1}^{N} K(D) K(P, T, D) \frac{10}{N}
$$

To insure uniform convergence of the numerical approximation to the integral, $N=N(T, P, T)$ where $\mathrm{T}_{1}$ is the shutdown time of the reactor. Let $\mathrm{T}$ and $\mathrm{T}_{1}$ be expressed in years. An empirical determination of $\mathrm{N}\left(\mathrm{T}, \mathrm{P}, \mathrm{T}_{1}\right)$ was used which insured proper convergence:

$$
\mathrm{N}=\frac{2}{365}+2\left|\mathrm{~T}-\mathrm{T}_{1}\right| \sqrt{\mathrm{P}}+4
$$

D may be expressed in terms of $\mathrm{N}$ and $\mathrm{i}$ :

$$
D=i \frac{10}{N}-\frac{10}{2 N}
$$

\footnotetext{
(2) $\mathrm{SC}-\mathrm{RR}-64-546$, Three Dimensional Surface Fit, M-151.
} 
Hence, $P_{m}(D, T)$ is defined in terms of $D, P_{m}(5, T)$, and $P_{m}(O, T)$. Consequently, $K(P, T, D)$ is determincd in terms of $\mathrm{P}_{\mathrm{m}}(\mathrm{D}, \mathrm{T})$ and arbitrary choice of $\mathrm{P} . \mathrm{K}(\mathrm{D})$ is determined by $\mathrm{D}$ and $\mathrm{so} K(\mathrm{P}, \mathrm{T})$ can be found for arbitrary $\mathrm{P}$ and $\mathrm{T}$. This defines the power history probability space contingent on initial equilibrium power and with $\mathrm{NaK}$ flow degradation.

Equation 12 expresses mean power history.

$$
\bar{P}(T)=\int_{0}^{2 P} P(T) K(P, T) d P .
$$

A table of $K\left(P_{i}, T\right)$ values are calculated using the integration scheme for $K(P, T)$. A printout of this set shows that it is a smooth function of $P$, hence an integer limit, 50, has been set as the index of the integration for $\overline{\mathrm{P}}(\mathrm{T})$.

$$
\widehat{P}(T)=\sum_{i=1}^{50} P(T) K\left(P_{i}, T\right) \frac{2 P_{m}(T)}{50}--
$$

$K\left(P_{i}, T\right)$ is taken from the above calculated table, $P_{m}(T)=\max \left|P_{m}(D, T)\right|$ from Equation 5 , and

$$
P(T)=-P_{m}(T) \quad 2 P_{m}(T)
$$

Because of the nature of Equation 5, which is an nth degree polynomial, slight wiggles in the curves for small $T$ result in $\max \left|P_{m}(D, T)\right|>P_{m}(O, T)$. The maximum value of $P_{m}(P, T)$ is determined within program DECIDE. Hence $\overline{\mathrm{P}}(\mathrm{T})$ is determined.

Equation 13 expresses the maximum power history with cumulative probability:

$$
C\left(P_{i}, T\right)=\int_{0}^{P_{i}} K(P, T) d P .
$$

The values of $\mathrm{P}_{i}$ that were used to define $\mathrm{K}\left(\mathrm{P}_{i}, T\right)$ will be used as the limit in Equation 13 . A table of $\mathrm{C}\left(\mathrm{P}_{\mathrm{i}}, \mathrm{T}\right)$ values will be calculated, just as a table of $\mathrm{K}\left(\mathrm{P}_{\mathrm{i}}, \mathrm{T}\right)$ was determined. Notice that the cululative probability $C$ is expressed explicitly, whereas $P$ is implicit.

$$
\begin{aligned}
C\left(P_{i}, T\right) & =P_{m}(T) K\left(P_{1}, T\right) \\
50 & +\sum_{j=2}^{i-1} 2 P_{m}(T) K\left(P_{j}, T\right) \\
& +P_{--}(T) K\left(P_{i}, T\right)
\end{aligned}
$$

where additional terms must be included to account for integration at the beginning and end of the interval of integration. When a table of $\mathrm{C}\left(\mathrm{P}_{\mathrm{i}}, \mathrm{T}\right)$ has been calculated, interpolation within the table determines $\mathrm{P}(\mathrm{C}, \mathrm{T})$. 
The table of $\mathrm{C}\left(\mathrm{P}_{1}, \mathrm{~T}\right)$ consists of values between 0 and 1 in theory and as calculated by DECIDE. By choosing a particular value of $C$, the maximum power history with cumulative probability $C$ is defined.

The output from DECIDE includes $K(P, T), C\left(P_{i}, T\right), P(C, T)$, and $\bar{P}(T)$. The values of $T$ used were $1,2, \ldots, 10$ days $; 1,2, \ldots, 10$ years $, 1,2, \ldots, 10$ decades $; 1,2, \ldots, 10$ centuries; and $1,2, \ldots$. , $10 \mathrm{~K}$ years. Fifty equal increments of $\mathrm{P}$ are chosen between zero and the maximum possible power. Cumulative values of $\mathrm{J} / 10, \mathrm{~J}=1,2, \ldots, 10$ are used to define ten cumulative powers.

The need to relate power history to hazard potential requires the solution of the fission product buildup problem. A computer program of considerable versatility, entitled CURIE-DOSE, has bcen written by Atomics International. Not only can a power history in a reactor be used as input to this code, but doses are calculated directly by the code.

Some program modification was performed by Sandia Corporation to facilitate input of power histories. A separate data preparation program accepts power and time data and modifies its form to be compatible with CL'RIE-DOSE format. Output from CURIE-DOSE has been modified to include only rem/hr at $1 \mathrm{foot}$. It has been assumed that the effective whole-body dose is numerically equal to $\mathrm{rem} / \mathrm{hr}$ at 1 foot; that is, the net damage effect is the same as if the entire body were just 1 foot from the fuel element. This assumption approximates the hazard when the fuel element is clutched in the hand, carried in a pocket, or carried in a handbag. A typical dose rate curve following shutdown is shown in Figure 3.

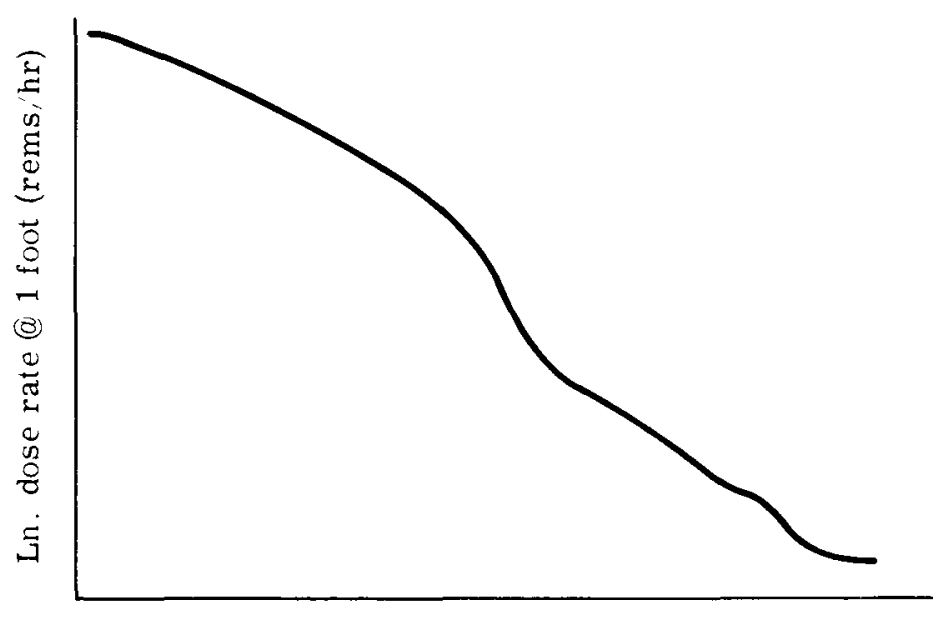

Ln, time from sbutdown (hrs)

Figure 3. Dose Rate versus Time from Shutdown (Typical)

\section{Conclusion}

Generalized procedures for studying a multiplicity of situations may be used to generate a fission product versus time probability space useful in determining hazard. In addition to the procedures outlined here, which may be developed for a variety of aerospace reactors, it is required that one have available means of ascertaining power-time history and for solving the fission product and/or dose history problem given power-time history. 


\section{DIST RIBL TION}

tandard Aerospace Nuclear Safety Distribution $(2,0)$

V I Blake, 9310

II. I. Hansen, 9311

†. T. Clark, Jr., $9312(5)$

A. 1. Bentz, 9313

J. II Nichieinan, 9319, Attn T. S. F drungton

B. R. 111en, 3421

II. C. Rindle, $428-1$, Bldg. 802

II. 1. Carstins, 3410 , Attn T. B. Heaphy, 3411

R. Y. Crllespie, 3413 (2)

II. I. Jamic son, 8232

R. C. Smelich, 3415-3(10)

saued b; Sondia Corporation

a fime contractor to the

in ted btates Atomic Energv Commission

\section{LE G A L N O T I C E}

This report was prepared as an account of Government sponsored work Veithe $\mathrm{I}$ the I nited states, not the Commission, nor any person acting on behalf of the commission

1 Vake any warranty or representation, expressed or implied, with re spect to the accuracy, completent $s a$, or ucefulness of the information contained 11 this report of that the use of any information, apparatus, method, or process discloned in this report may not infringe privately owned rights or

13 Lsumes any liabilities $w 1$ th respect to the use of, or for damages resultug fron the use of any information, apparatus, method, or process disclosed in this report

is used in the above, "person acting on behalf of the Commission" includes any employet or contractor of the Commission, or employee of such contractor, to the extent that such emploree or contractor of the Commer to the extent hat such emplovee or contractor or the Commission, or employce or such contrat tor prepares, disseminates, or provides access to, any information pursuant to his employment or contract with the Commission, or his employment uith such contractor

Printed in I SA. Price \$1.00. Avallable from the Clearinghouse for I ederal Si if ntific and I c chnical Information, National Bureau of Standards,

L. S. De partme in of commerce, Springfield, Virginia 